\title{
Effect of Fireworks, Chinese New Year and the COVID-19 Lockdown on Air Pollution and Public Attitudes
}

\author{
Peter Brimblecombe ${ }^{1,2}$, Yonghang $\mathrm{Lai}^{3^{*}}$ \\ ${ }^{1}$ Department of Marine Environment and Engineering, National Sun Yat-Sen University, Kaohsiung 80424, Taiwan \\ ${ }^{2}$ Aerosol Science Research Center, National Sun Yat-Sen University, Kaohsiung 80424, Taiwan \\ ${ }^{3}$ School of Energy and Environment, City University of Hong Kong, Hong Kong
}

\begin{abstract}
Concentrations of primary air pollutants are driven by emissions and weather patterns, which control their production and dispersion. The early months of the year see the celebratory use of fireworks, a week-long public holiday in China, but in 2020 overlapped in Hubei Province with lockdowns, some of $>70$ days duration. The urban lockdowns enforced to mitigate the COVID-19 pandemic give a chance to explore the effect of rapid changes in societal activities on air pollution, with a public willing to leave views on social media and show a continuing concern about the return of pollution problems after COVID-19 restrictions are lifted. Fireworks typically give rise to sharp peaks in $\mathrm{PM}_{2.5}$ concentrations, though the magnitude of these peaks in both Wuhan and Beijing has decreased under tighter regulation in recent years, along with general reductions in pollutant emissions. Firework smoke is now most evident in smaller outlying cities and towns. The holiday effect, a reduction in pollutant concentrations when normal work activities are curtailed, is only apparent for $\mathrm{NO}_{2}$ in the holiday week in Wuhan (2015-2020), but not Beijing. Lockdown in Wuhan was characterised by decreases in $\mathrm{NO}_{2}$, along with more subtle changes in particulate matter and other pollutants. Ozone noticeably increases as there is less NO available for titration, but such change may not be widespread geographically. Beijing, where restrictions were less stringent, showed some improvement in air quality, though this is more difficult to detect, even within the $5^{\text {th }}$ Ring Road.
\end{abstract}

Keywords: Beijing; Holiday effect; Social media; Weekend effect; Wuhan.

\section{INTRODUCTION}

Shifts in the pattern of human behaviour can dramatically change local air quality. Daily or weekly cycles are the most obvious, but the effects of holidays are also well known. Conveniently, social and work patterns differ country to country. Large events such as the Olympic Games or World Cup can change local policies and effectively alter environmental quality (Preuss, 2013). Significant events such as APEC meetings (Wang et al., 2018; Brimblecombe and Zong, 2019) or public celebrations such as the Victory Parade (Wang et al., 2017) may also have a short term impact on air pollution by reducing urban emissions, while political demonstrations and protests can block traffic and also affect air pollution at a local level (Brimblecombe and Ning, 2015; Brimblecombe, 2020a) and may see themselves linked to issues of emissions e.g., gilets jaunes (Kinniburgh, 2019).

The weekend effect, arising because differing pollutant emissions between weekdays and weekends, reflects a

\footnotetext{
* Corresponding author.

E-mail address: yonghalai2-c@my.cityu.edu.hk
}

regular pattern in human activity. This is relatively easy to identify, so received comment in Victorian cities where pollution was argued to derive from cooking Sunday roast dinners (Brimblecombe, 1987). Today, pollutants such as $\mathrm{CO}, \mathrm{NO}_{\mathrm{x}}, \mathrm{NO}_{2}, \mathrm{SO}_{2}$ and $\mathrm{PM}_{2.5,10}$ are typically found to be higher on weekdays, because of rush hour traffic, work patterns and industrial activities, but also influenced by population and urbanization (Qin et al., 2004; Riga Karandinos, 2005; Pudasainee et al., 2010; Sadanaga et al., 2012; Wolf et al., 2013; Cerro et al., 2014; Porter et al., 2014; Henschel et al., 2015; Malik et al., 2015; Martins et al., 2015). Ozone as a secondary photochemical oxidant, shows more complex behavior: lower on weekdays than on weekends (Tang et al., 2008), although sometimes it can also be higher during the week (Huryn et al., 2014; Xie et al., 2016).

The holiday effect refers to changed air pollutant concentrations that arise at vacation times or holidays. This is illustrated by the dramatic changes that come about from the decrease of primary pollutant emissions during the Day of Atonement (Levy, 2013) or the celebration of Mid-Autumn Festival in Taiwan where families cook on barbecues (Tsai et al., 2015). The holiday effect can be studied over extended periods, often extending beyond a weekend, e.g., New Year or Spring Festival, as celebrated in Asia, perhaps the most 
important festivals of the Chinese lunar calendar. Tan et al. (2009) revealed the concentrations of $\mathrm{NO}_{\mathrm{x}}, \mathrm{CO}$, non-methane hydrocarbons, $\mathrm{SO}_{2}$ and $\mathrm{PM}_{10}$ in Taiwan from 1994 to 2006 were lower across the New Year holiday than the non-holiday times, although the concentration of ozone was higher, i.e., $\mathrm{NO}_{\mathrm{x}}$ titration absent. Chen et al. (2014) showed significant reductions of $\mathrm{PM}_{2.5}$ and $\mathrm{PM}_{10}$ in 31 Chinese cities, while Gong et al. (2014) reported decreased concentrations of key air pollutants.

The New Year is welcomed with large quantities of fireworks, so there is also a significant potential for increased pollution. There have been many attempts by the Chinese government to reduce fireworks since the 1980s, though not codified until 1992 (Zhou and Zhou, 2018). The early morning hours of the New Year can experience some of the highest particulate loadings of the year, and concentrations at some locations can exceed $1000 \mu \mathrm{g} \mathrm{m}^{-3}$ (Huang et al., 2012; Zhao et al., 2014; Kong et al., 2015; Ye et al., 2016; Lai and Brimblecombe, 2017; Ji et al., 2018; Yuan et al., 2020). The firework-derived pollutants are not spatially homogeneous, rather these are dependent on the level of regulatory enforcement and shifts towards public firework displays (Lai and Brimblecombe, 2017; Yao et al., 2019; Lai and Brimblecombe, 2020).

The impact of the global spread of COVID-19 has led to global restrictions on population movement. Although such restrictions are not historically unique (Brimblecombe, 2020b) in the 20th century these have led to emissions reduction (e.g., Safarian et al., 2020; Sharma et al., 2020) from factories and transport systems and a changed electricity demand (Narajewski and Ziel, 2020). Yue et al. (2020) suggest carbon emissions decreased by $9.8 \%$ in 2020 compared to February-March/2019. Reduced emissions have allowed numerous observations of reduced air pollutants from satellite (Bauwens et al., 2020) and within China (Bao and Zhang, 2020; Cole et al., 2020; Dutheil et al., 2020; Liu et al., 2020; Muhammad et al., 2020; Wang and Su, 2020; Xu et al., 2020; Yue et al., 2020), India (Sharma et al., 2020), South East Asia (Abdullah et al., 2020; Mohd Nadzir et al., 2020), Europe (Lewis, 2020; Tobías et al., 2020), US (Muhammad, et al., 2020) and South America (Dantas et al., 2020; Nakada and Urban, 2020). The work has often been at an early stage and publications difficult to assess (London et al., 2020; Servick and Enserink, 2020). Many are simple comparisons with the preceding months or the same season of 2019, with Cole et al. (2020) rightly suggesting a nuance to air quality during lockdown that reporting has failed to acknowledge. Some have argued that peak air pollution concentrations remain (Wang et al., 2020), while Shi and Brasseur (2020) suggest health risks from the increased ozone (Huang et al., 2020), along with sensitization of populations that has been imposed by prior exposure to air pollutants (Wu et al., 2020).

Here we link changes in the pattern of human activity in the early months of 2020, as reflected in air pollution in Beijing and Wuhan. In particular, the study examines the differing effects of holidays, lockdown, and celebratory fireworks on air quality as touched upon by Yang et al. (2020). We wish to emphasise a subtlety to changes in air quality imposed by lockdown that are often lost in more sweeping generalisations in the media (Cole et al., 2020). The work makes use of comments on social media that hint at societal viewpoints, an important consideration in policy making. It establishes differences imposed by recent events, but also considers potential for changes in exposure and reflects on what COVID-19 might mean for longer term policy.

\section{METHODS}

This study focuses on Beijing, China's capital (Fig. 1) with a population of more than 21 million in the urban area covering some 4,144 $\mathrm{km}^{2}$ and Wuhan (Pop. 11 million; 2018) one of the nine National Central Cities of China (Fig. 1), along with three nearby a prefecture-level cities of Hubei Province: Huanggang (7.4 million; 2017), Ezhou (1.05 million; 2010) and Huangshi (2.4 million; 2010). The air pollution data comes from official records (http://aqicn.org/city/) in and around Beijing (12 urban within the $5^{\text {th }}$ Ring Road and 11 suburban sites outside this Road), from ten sites in Wuhan and three from Huanggang and Ezhou and five from Huangshi. The records are available at hourly intervals for six pollutants: $\mathrm{NO}_{2}, \mathrm{PM}_{2.5}, \mathrm{PM}_{10}, \mathrm{CO}, \mathrm{SO}_{2}$ and $\mathrm{O}_{3}$. They typically become available from 2014, although some limited earlier records can be found. The contribution of fireworks to airborne particles requires a correction to be made for other sources. In this study, this was made using CO concentration as fireworks release relatively small amounts ( $\mathrm{Li}$ et al., 2006). The correction factor was established from the ratio of average $\mathrm{PM}_{2.5}$ and $\mathrm{CO}$ concentrations, which can be well correlated during non-firework periods (as in Wang, 2015); the non-firework period selected here were the 14 days before the Chinese New Year. The contribution of fireworks to the particulate load was calculated by the subtraction.

The Chinese New Year is set by the lunar calendar as: 10 Feb 2013, 31 Jan 2014, 19 Feb 2015, 8 Feb 2016, 28 Jan 2017, 16 Feb 2018, 5 Feb 2019 and 25 Jan 2020. However, the statutory holiday period in Mainland China starts on the Eve of Chinese New Year and covers seven days. In 2020, this was extended by two further days because of the coronavirus epidemic. Wuhan was at the centre of the pandemic and as it became necessary to contain the disease in Hubei province, the central government suspended all public transport in Wuhan from the morning of 23/January/2020; the first time in history a megacity had entered lockdown. Within hours, travel restrictions were also imposed on nearby Huanggang and Ezhou and in Huangshi the next day. The streets of Wuhan became silent and the once-bustling city a ghost town. Although grocery stores and some shops remained open, most people stayed at home only making the most essential of trips outside. Lockdown ended in Huangshi on the 13/March and in Huanggang and Ezhou on 25/March. Wuhan remained under lockdown until 8/April.

In Beijing, there was no strict lockdown policy, but the government suggested people remain indoors, and while outside adopt social distancing. Beijing authorities cancelled events and closed some major tourist attractions, including the Forbidden City and the National Maritime Museum (> 24/January) and the Palace Museum (> 25/January) through to the end of April. 


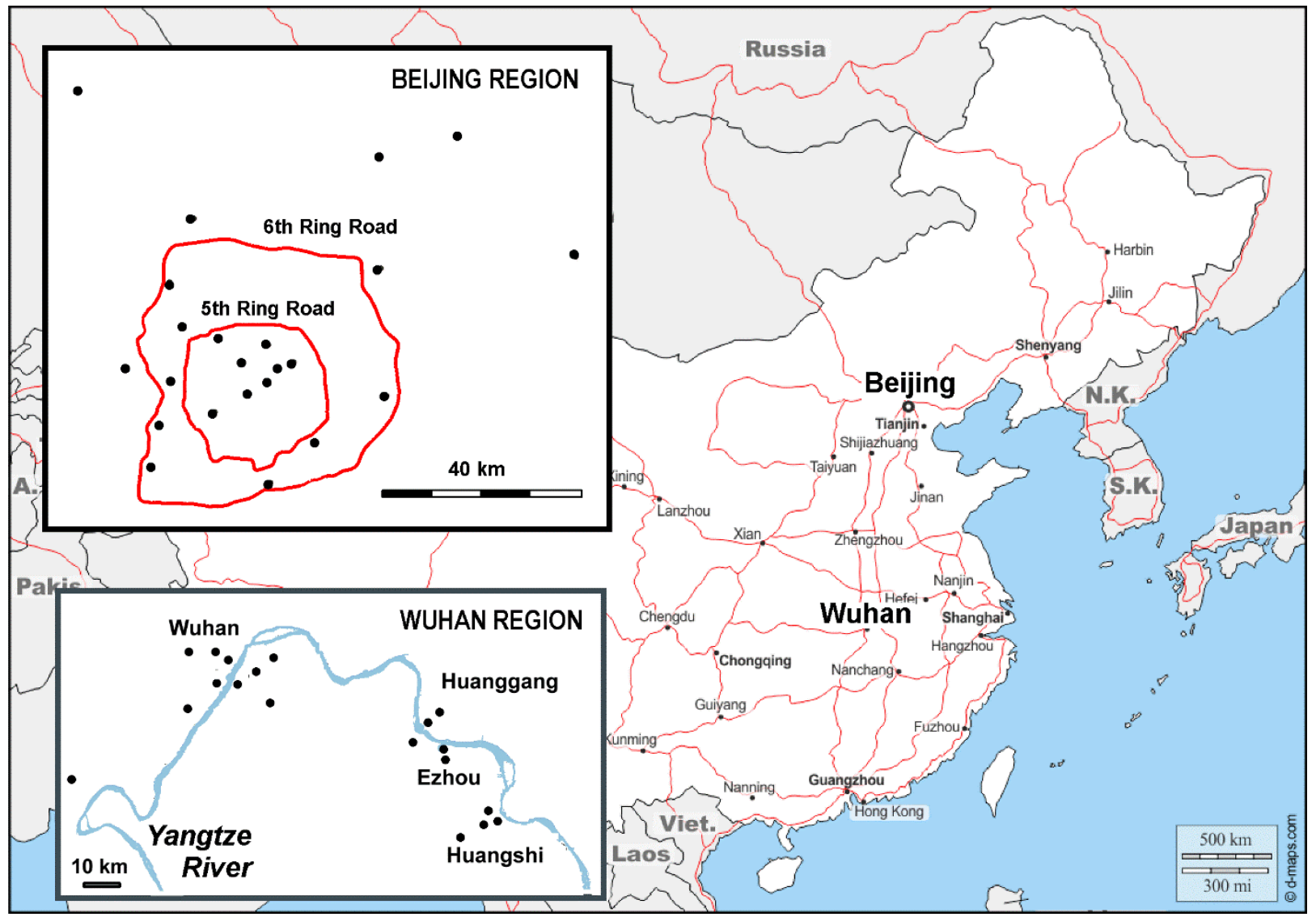

Fig. 1. Map showing the monitoring sites in Wuhan and Beijing.

Hardly surprising, the lockdown and closures led to considerable comment on social media, which provides useful insights on public attitudes (Brimblecombe and Zong, 2019) that can be useful in formulating environmental policies (Deguen et al., 2012). This is especially true with commentary on fireworks as these are difficult to purchase and their use often restricted, so information can be easiest to follow on social media (Lai and Brimblecombe, 2020). We obtained social media content of postings to SinaWeibo (https://www.weibo.com) using the combined advanced search and the characters "Wuhan fireworks" from 1/January to 30/April, in both 2019 and 2020 and to a lesser extent Beijing. Additionally, attitudes of Wuhan residents to changes in air pollution during lockdown were explored by gathering data with the search terms "Wuhan lockdown". The data from the two years were compared using the log-likelihood and effect size calculator available at (http://ucrel.lancs.ac.u k/llwizard.html) from Lancaster University, which uses loglikelihood (LL) to assess where it is probable that the null hypothesis can be rejected and allow us to assess differences in the frequency of occurrence. The more familiar chisquared test could have been used, but it is difficult to apply where there are few instances of particular concepts found in the social media posts.

Statistical calculations have benefited from Vassarstat (http://vassarstats.net/). The $t$-test was used in Student's and Welch's form, the latter appropriate for unequal variance. The ANOVA calculator (for either independent or correlated samples) to compare sites for different periods of the year (i.e., before, during and after Chinese New Year) and occasionally, its non-parametric equivalent, the Friedman test (test statistic $Q$, which approximates to $\chi^{2}$ the common probability distribution used in inferential statistics), with Tukey's HSD test used to assess comparisons.

\section{RESULTS AND DISCUSSION}

\section{Seasonal and Secular Change in Air Pollutants}

Fig. 2 shows the secular change of pollutants in Beijing and Wuhan from 2013 for (a) $\mathrm{NO}_{2}$, (b) $\mathrm{PM}_{2.5}$, (c) $\mathrm{PM}_{2.5}$, (d) $\mathrm{CO}$, (e) $\mathrm{SO}_{2}$, and (f) $\mathrm{O}_{3}$, and also gives hints of the seasonal change. It shows that primary pollutants have typically been in decline in Beijing and Wuhan as they have for much of China (Cheng et al., 2018). These secular improvements in Wuhan are also nicely seen in the plots 2013-2020 from Cole at al. (2020), which remove weather effects and for Beijing in $\mathrm{Vu}$ et al. (2019). Fig. 2 also suggests that in general the early part of the year sees improving air quality, although ozone typically rises through the year and shows summer maxima.

\section{Contribution from Fireworks}

The early months of the year are traditionally celebrated with fireworks as part of Spring Festival, but there have been persistent attempts by the government to reduce this pollution source (Zhou and Zhou, 2018). Although these have not 

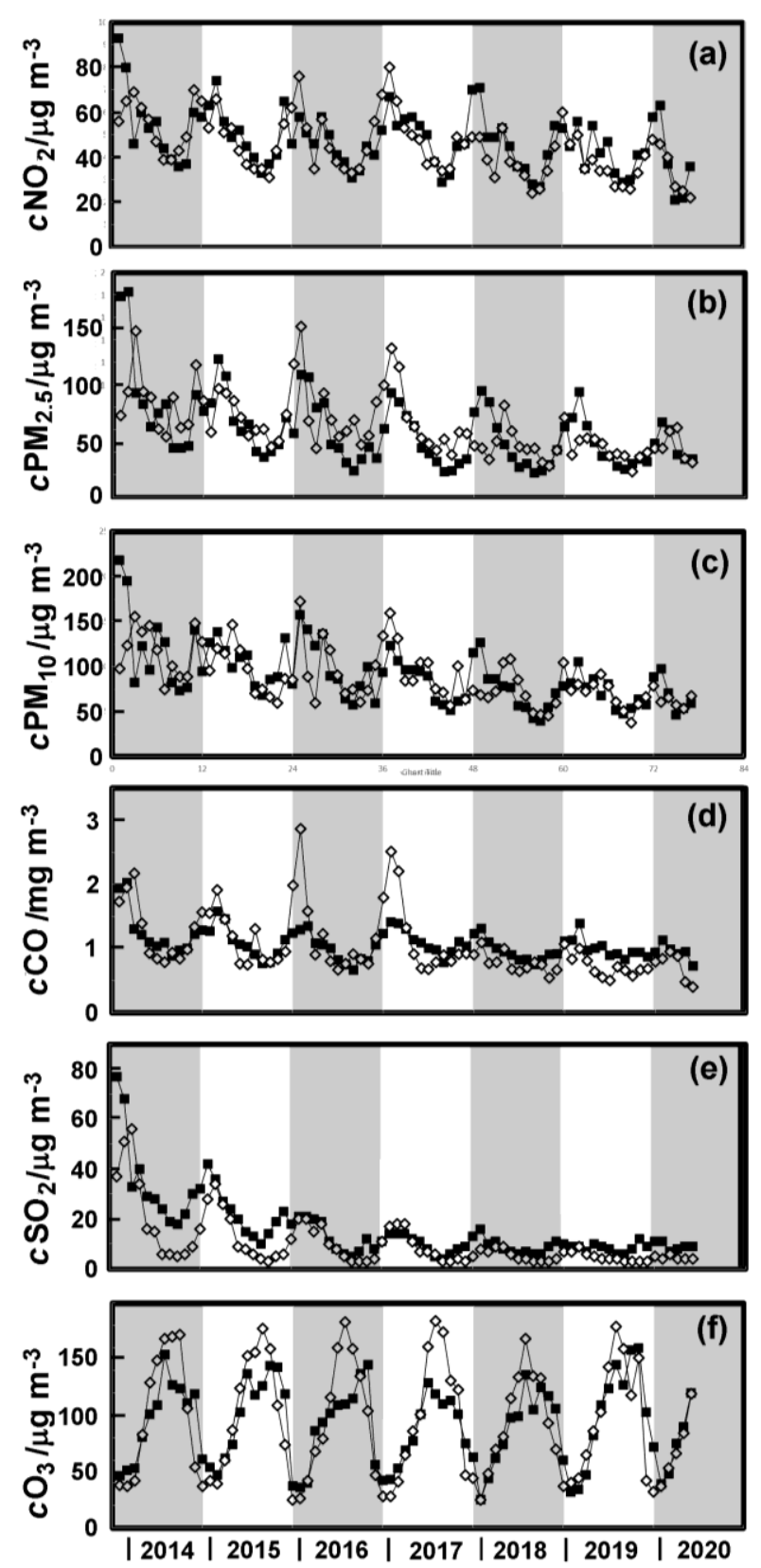

Fig. 2. Monthly average concentrations (a) $\mathrm{NO}_{2}$, (b) $\mathrm{PM}_{2.5}$, (c) $\mathrm{PM}_{10}$, (d) $\mathrm{CO}$, (e) $\mathrm{SO}_{2}$ and (f) $\mathrm{O}_{3}$ across all sites in Wuhan (squares) and Beijing (open diamonds) from December 2013 to April 2020. Shading denotes 12-month periods.

always been effective, efforts have become more concerted in the present decade, which has seen reductions in emissions even though fireworks remain popular (Yao et al., 2019; Lai and Brimblecombe, 2020). The particulate matter once characteristic of the celebrations in Beijing (Li et al., 2006; Wang et al., 2016; Sun, 2017; Hu et al., 2019) has been reduced in recent years and firework smoke is less evident within the $5^{\text {th }}$ Ring Road (Lai and Brimblecombe, 2020). Fig. 3(a) shows that the sharp peaks in $\mathrm{PM}_{2.5}$ from fireworks typical of the early hours of New Year are no longer apparent in the capital. In 2020 (bold dark curve), there was no evidence of a peak characteristic of earlier years but given the concerns over public gatherings at the time it is hardly surprising. However, as is typical this better air quality at New Year did not extend to more rural areas (Fig. 3(b)). Peaks in particulate matter can still be seen at rural locations (Cui et al., 2020), with concentrations at almost $900 \mu \mathrm{g} \mathrm{m}^{-3}$ ( 02:00 hrs at Liulihe). Some posts to Weibo suggested firework displays, although many residents within the $5^{\text {th }}$ Ring Road did not see or hear any, so activities were restricted to more remote areas. There were comments that local government was messaging residents not to use fireworks, rather than giving hints on limiting COVID-19.

In Wuhan, fireworks have also been a source of pollutants (Han et al., 2014; Liu et al., 2017), so subject to official control. In theory, the early morning peak of $\mathrm{PM}_{2.5}$ evident in 2013 should not recur (Fig. 3(c)), yet there was a noticeable peak in 2016 across much of the city. The increase begins just after midnight and is not associated with a parallel increase in $\mathrm{CO}$, so suggests it likely derives from fireworks (Lai and Brimblecombe, 2017, 2020) and supported by some Weibo posts about the illegal fireworks. High particulate concentrations were not evident at Yuanshun Road (site 1334A), near the important Chenhu wetland, the site of the Late Imperial story A Corpse's Transmutation by Pu Songling. In the neighboring city of Huangshi (see map Fig. 1) restrictions are in place, but in Huanggang to the southeast of Wuhan fireworks are less restricted, so there are noticeable peaks in $\mathrm{PM}_{2.5}$ at New Year.

The New Year of 2020 was naturally a more restrained event. Although there was a noticeable peak in $\mathrm{PM}_{2.5}$ concentration about 05:00 on 25/January at sites in Wuhan (bold line Fig. 3(c)), it is unlikely to derive from fireworks, because there is a parallel peak in $\mathrm{CO}$, so may be the early morning transfer of supplies and human assistance to the beleaguered city. In 2020, there are small, but noticeable peaks in $\mathrm{PM}_{2.5}$ late on the Eve of the New Year in Huangshi, Ezhou and Huanggang (Fig. 3(d)), but these are smaller than peaks ascribed earlier to non-firework activities, in Wuhan.

Some posts to Weibo from Ezhou said that the sound of fireworks could be heard from rural areas and suggested their decrease in use or the resultant quiet and tranquility; comments frequently found in 2020. While the year of lockdown saw fewer posts about fireworks, many expressed a desire for displays even in such tragic times (Table 1), so the percentage enthusiastic about fireworks rose more than ten-fold (1.4-16.7\%). Nevertheless, there were still a few posts, in both 2020 and 2019, mentioning bans on the use of firework, but little comment on illegal sales, which have been a problem in the past (Lai and Brimblecombe, 2020). There were some posts reflecting concern over safety issues or accidents with fireworks and the resultant smoke haze, though not significantly different $(p>0.05)$ between the two years. Although there was little change in the frequency of comment on the cultural relevance of fireworks, social media revealed a significant increase $(p<.0001)$ in comments on Nian traditions. It appeared that residents during the pandemic remained attached to ancient notions that burning fireworks would drive away the epidemic, which could be seen as an evil spirit.

There is evidence that cities have much reduced the use 

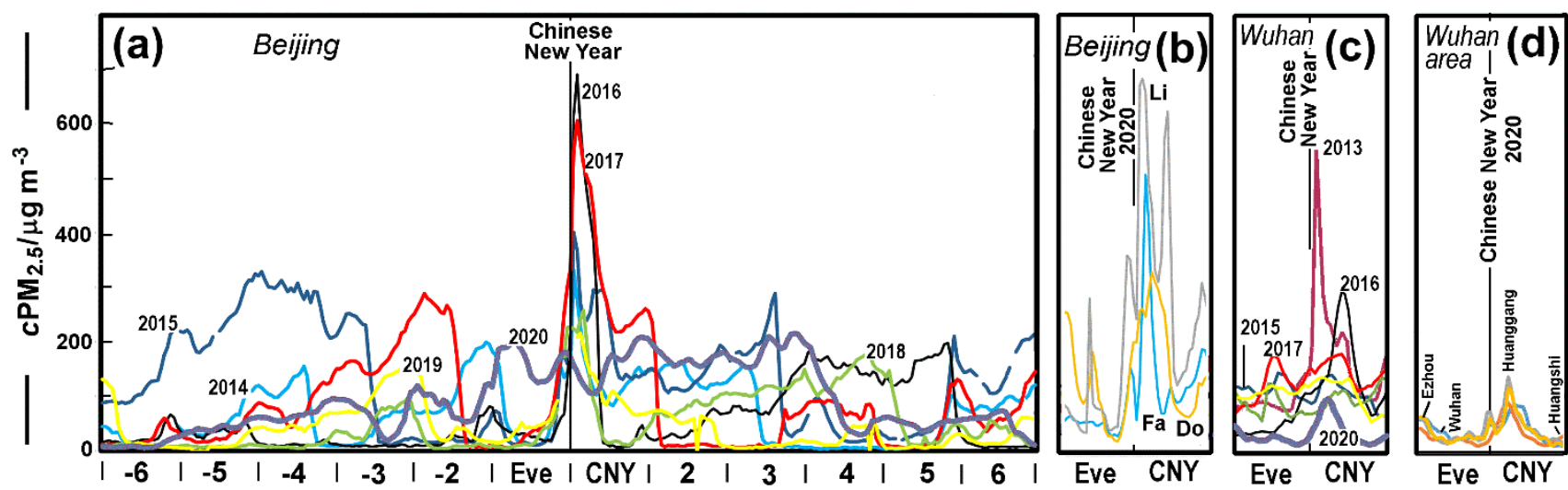

Fig. 3. $\mathrm{PM}_{2.5}$ concentrations (a) Averaged for urban and suburban stations in Beijing for six days and six days after Chinese New Year. (b) Particulate matter on the eve and first day of the New Year of 2020 less central sites of Fangshan (Fa- blue line) Donggaun (Do- yellow line) and Liulihe (Li- gray line). Averaged for urban and suburban stations in Wuhan. (d) Averaged $\mathrm{PM}_{2.5}$ for sites in Huangshi, Ezhou and Huanggang for the eve and first day of the New Year of 2020. Note: Scale of (b) is slightly different and spans $1000 \mu \mathrm{g} \mathrm{m}^{-3}$.

Table 1. Key concepts identified within raw counts and frequency as a percentage from posts on social media from 1/January-30/April, in 2019 and 2020. Note the log-likelihood value (LL) 5\% critical value at LL = 3.84 (p < 0.05 ; denoted $*$ ) and $0.01 \%$ critical value $\mathrm{LL}=15.13$ ( $\mathrm{p}<0.000$; denoted $* *)$.

\begin{tabular}{llllll}
\hline Concept & 2019 & $\%$ & 2020 & $\%$ & LL \\
\hline Corpus size: posts & 2387 & & 785 & & \\
Heard/saw fireworks & 41 & 1.7 & 145 & 18.5 & $223^{* *}$ \\
Decreasing use (description) & 1 & 0.04 & 10 & 1.3 & $22^{* *}$ \\
Quiet & 9 & 0.4 & 18 & 2.3 & $21^{* *}$ \\
Enthusiastic about fireworks & 33 & 1.4 & 131 & 16.7 & $220^{* *}$ \\
Against fireworks & 4 & 0.2 & 14 & 1.8 & $22^{* *}$ \\
Ban (description) & 67 & 2.8 & 37 & 4.7 & $6^{*}$ \\
Illegal sales (description) & 21 & 0.9 & 6 & 0.8 & 0.6 \\
Concerns safety-accidents & 49 & 2.1 & 12 & 1.5 & 0.9 \\
Firework smoke (description) & 12 & 0.5 & 5 & 0.6 & 0.2 \\
Cultural importance & 8 & 0.3 & 5 & 0.6 & 1.2 \\
Loss of Nian culture & 22 & 0.9 & 28 & 3.6 & $22^{* *}$ \\
\hline
\end{tabular}

of fireworks, but emissions are still reflected in high particulate concentrations at more rural locations and smaller towns and cities, where the bans have not been set or not enforced. Such regulatory heterogeneity can be found elsewhere, so while sharp peaks in $\mathrm{PM}_{2.5}$ are no longer so common in Chinese cities, they remain a characteristic of the less populated areas that surround these cities (Lai and Brimblecombe, 2017, 2019).

As many on Weibo had expressed the desire to see fireworks: "although Wuhan banned the fireworks in urban areas this year, I really hope the government will allow residents to have fireworks in this special year. It represents a victory on this White War". There was evidence of such celebrations after lockdown ended in early April. Social media suggests that some Wuhan residents went to Ezhou and there are hints of a distinct peak of $\mathrm{PM}_{2.5}$ between 19:00 and 21:00 on 8/April (Fig. 4(a)). This is likely to derive from fireworks as tuning the data with $\mathrm{CO}$ concentrations fails to remove the peak (Fig. 4(b)), as described in the method. A few posts to Weibo mentioned that they observed some small firecrackers at the end of the lockdown in outlying suburban areas. Most of the celebrations of the end of lockdown took place in Wuhan a few days later, with a broad peak of pollutants (Figs. 4(c) and 4(d)) in the early morning hours of the 10 April (Good Friday, though Easter is not celebrated in China); this supports claims of fireworks found on Weibo, which even extended to the rural site in the Chenhu wetlands (black line Fig. 4(c)).

\section{Holiday Effect on Air Pollutants}

The data were split into three periods (i) the two weeks prior to New Year's Eve, (ii) the seven days across the holiday and (iii) the two weeks following. The general expectation would be that the holiday week would have lower emissions, which is essentially at the heart of the holiday effect. However, seasonal change occurs across this period so the meteorology is not constant, and the picture can readily become more confused as illustrated in Fig. 5.

In the case of $\mathrm{NO}_{2}$, the Chinese New Year in Wuhan shows the lowest average concentrations (Fig. 5(a)), although unsurprisingly 2020, with its lockdown after the New Year meant concentrations were low beyond the formal holiday 


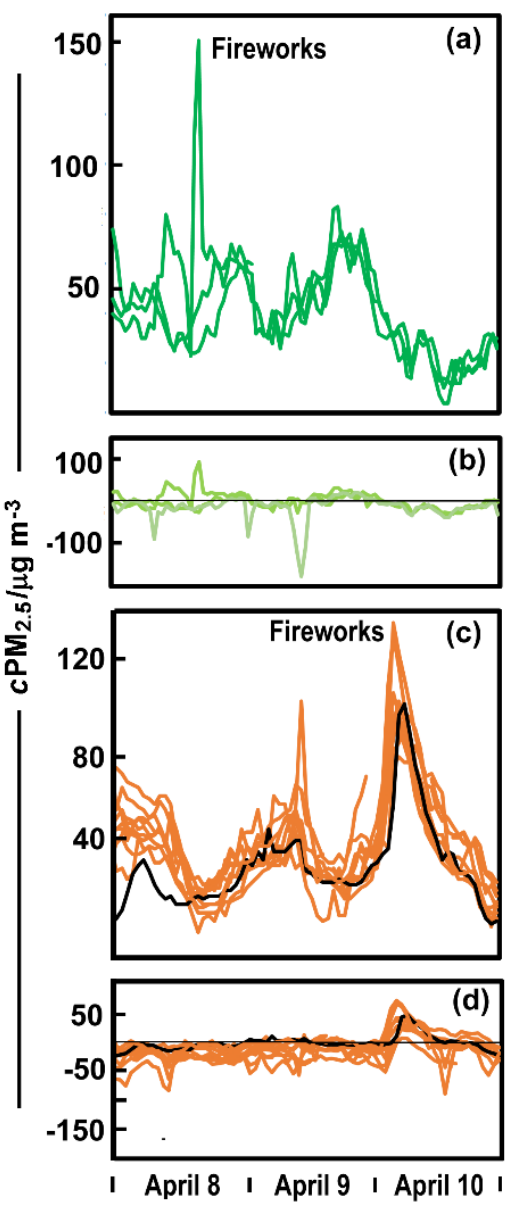

Fig. 4. Particulate matter concentrations on the days after the lockdown ended in Wuhan. (a) $\mathrm{PM}_{2.5}$ from the three sites in Ezhou. (b) $\mathrm{PM}_{2.5}$ concentrations in Ezhou corrected for nonfirework sources using $\mathrm{CO}$ concentrations. (c) $\mathrm{PM}_{2.5}$ from the nine sites in Wuhan with the remote in Chenhu wetlands as a dark line. (d) $\mathrm{PM}_{2.5}$ concentrations in Wuhan corrected for non-firework sources using $\mathrm{CO}$ concentrations.

period. The average concentrations from all the sites available for the six years are as means for the three periods: (i) 55.6, (ii) 26.3 and (iii) $40.8 \mu \mathrm{g} \mathrm{m}^{-3}$. An ANOVA test (for correlated samples) suggests the difference is significant $p<.0001$ and the Tukey HSD test shows significant differences $(p<.01)$ for all three combinations of pairs. Although ANOVA is fairly robust against deviations from normality the three datasets were checked against the Friedman test (a nonparametric equivalent of the correlated ANOVA), which gave $Q=41.3$ and $(p<.01 ; n=55)$ and mean ranks for the three periods: 2.8, 1 and 2.2, with the holiday clearly lowest. As 2020 was so unusual in Wuhan the three periods were compared at the nine sites revealing once again the holiday period was the lowest: means (i) 39.7 , (ii) 17.8 and (iii) $21.2 \mu \mathrm{g} \mathrm{m}^{-3}$. In this case the Tukey HSD test revealed these differences of lower significance: (i):(ii) $p<.01$ (i):(iii) $p<.01$ and (ii):(iii) $p<.05$. The lower significance of the difference during the New Year and the following lockdown is visually apparent from Fig. 5(a), but the differences are supported by the Friedman test $(Q=16.2 ; p<.0003 ; n=9$ giving mean ranks for the periods as: $3,1.1$ and 1.9 .

The picture for particulate matter is less clear (Figs. 5(b) and 5(c)). The $\mathrm{PM}_{2.5}$ concentrations over the New Year holiday are higher than the period that follows for all years, but inconsistent when compared with the period before; a situation somewhat similar for $\mathrm{PM}_{10}$. Despite the lack of visual clarity in Fig. 5, the ANOVA suggests the holiday period is typically in the middle: 85,76 and $63 \mu \mathrm{g} \mathrm{m}^{-3}$; a significant difference $p<.0001$ with the Tukey HSD differences showing significant differences $(p<.01)$ for all three combinations of pairs. The statistics for other pollutants are listed in the top rows of Table 2. In Wuhan seasonal change imposes a general decline in pollutants except for ozone which increases (in line with Fig. 2). However, as shown in Figs. 5(d) and 5(f), the holiday effect is rather weak for the other pollutants in Wuhan. A confused picture is also found for Beijing in $\mathrm{NO}_{2}$ concentrations (Fig. 5(g)), where the holiday is not always a period of lower pollution. In the case of $\mathrm{PM}_{2.5}$, the holidays tend to be rather higher, these higher concentrations, perhaps resulting from fireworks. The statistical analysis for the pollutants in Beijing is given in the lower part of Table 2). Overall, the holiday effect is not especially distinctive and all what we can conclude is that Wuhan has lower $\mathrm{NO}_{2}$ in the holidays and Beijing higher particulate concentrations.

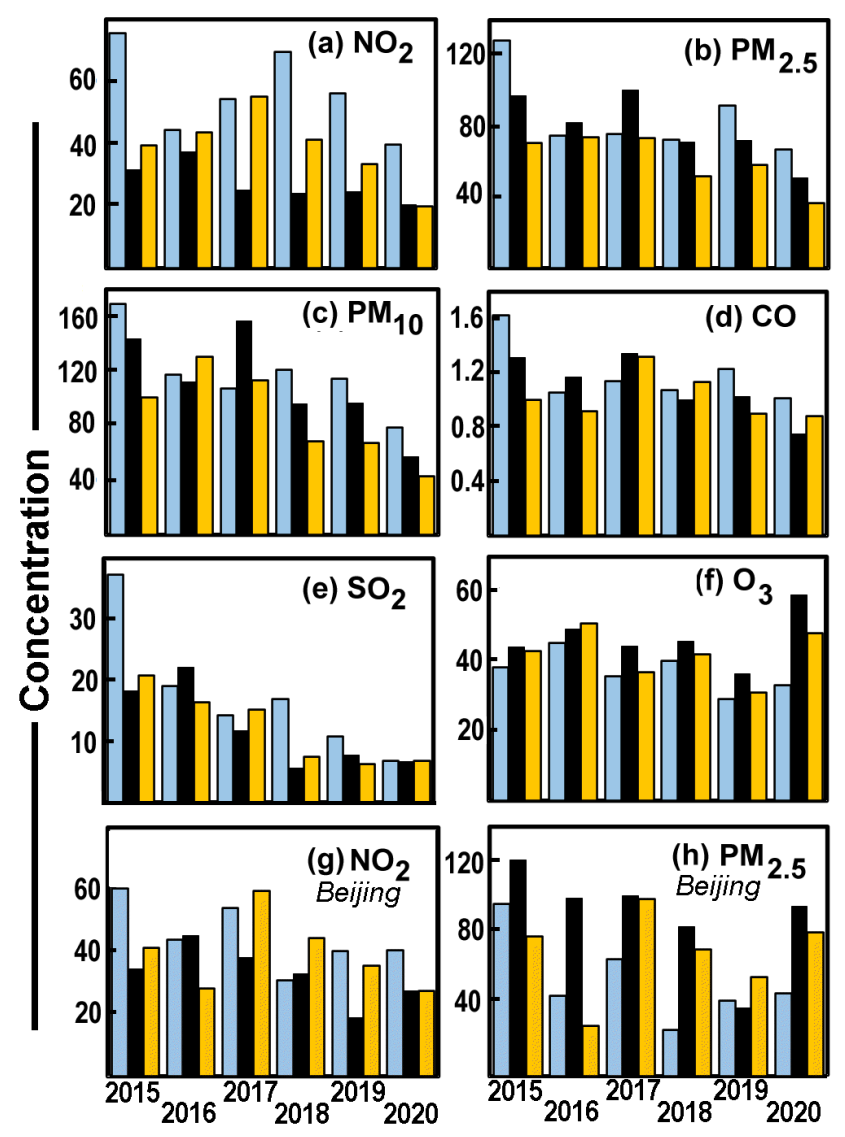

Fig. 5. Average pollutant concentrations before, during (black bar) and after Chinese New Year 2015-2020 for (a) $\mathrm{NO}_{2}$, (b) $\mathrm{PM}_{2.5}$, (c) $\mathrm{PM}_{10}$, (d) $\mathrm{CO}$, (e) $\mathrm{SO}_{2}$ and (f) $\mathrm{O}_{3}$ in Wuhan and (g) $\mathrm{NO}_{2}$ and (h) $\mathrm{PM}_{2.5}$ in Beijing. Note: concentrations as $\mu \mathrm{g} \mathrm{m}^{-3}$, except $\mathrm{CO}$ as $\mathrm{mg} \mathrm{m}^{-3}$. 
Table 2. Average pollutant concentrations before, during and after Chinese New Year (2015-2020) used in the ANOVA, on correlated samples, with the Tukey HSD test indicating the significance $(p)$ of the differences between the New Year, and before and after. Note: $\mathrm{ns}=$ not significant concentrations $\mu \mathrm{g} \mathrm{m}^{-3}$, except $\mathrm{CO}$ as $\mathrm{mg} \mathrm{m}^{-3}$, Beijing is taken from the 23 urban and suburban sites.

\begin{tabular}{clllll}
\hline Pollutant & Before & $p$ & During & $p$ & After \\
\hline Wuhan & & & & & \\
$\mathrm{NO}_{2}$ & 56 & $<.01$ & 26 & $<.01$ & 41 \\
$\mathrm{PM}_{2.5}$ & 85 & $<.01$ & 76 & $<.01$ & 63 \\
$\mathrm{PM}_{10}$ & 119 & $<.01$ & 103 & $<.05$ & 92 \\
$\mathrm{CO}$ & 1.19 & $\mathrm{~ns}$ & 1.15 & $<.01$ & 1.05 \\
$\mathrm{SO}_{2}$ & 18 & $<.01$ & 11 & $\mathrm{~ns}$ & 13 \\
$\mathrm{O}_{3}$ & 38 & $<.01$ & 44 & $\mathrm{~ns}$ & 43 \\
Beijing & & & & 4.01 & 69 \\
$\mathrm{NO}_{2}$ & 38 & $<.01$ & 47 & $<.01$ & 71 \\
$\mathrm{PM}_{2.5}$ & 54 & $<.01$ & 125 & $<.01$ & 1.08 \\
$\mathrm{PM}_{10}$ & 69 & $\mathrm{~ns}$ & 1.19 & $<.01$ & 13 \\
$\mathrm{CO}$ & 1.13 & $<.01$ & 19 & $\mathrm{~ns}$ & 48 \\
$\mathrm{SO}_{2}$ & 16 & $<.01$ & 47 & & \\
$\mathrm{O}_{3}$ & 38 & & & \\
\hline
\end{tabular}

\section{Effect Lockdown on Air Pollutants/Quality}

Fig. 6 shows the concentration changes in a number of air pollutants in Wuhan and Beijing over the first four months of 2019 and 2020. Figs. 6(a) and 6(b) suggest a big change in $\mathrm{NO}_{2}$ averaged from all Wuhan sites after lockdown, compared with 2019, in line with observation of other research groups (Cole et al., 2020; Dutheil et al., 2020; Muhammad, et al., 2020; Wang and $\mathrm{Su}, 2020$ ). It is also possible to notice an apparent reduction in variance. However, the average concentrations are different, so this is not a fair test, hence the coefficient of variation ( $c_{\mathrm{v}}$ i.e., standard deviation/mean) for the individual sites were compared. The average values of $c_{\mathrm{v}}$ for $\mathrm{NO}_{2}$ across Wuhan in 2019 and 2020 were 0.425 and 0.364 , although a paired $t$-test suggests this difference is not especially significant $\left(p_{1}=0.05\right)$.

However, the rural site at Yuanshan Road is odd, with $c_{\mathrm{y}}$ in 2019 and 2020: 0.48 and 0.56, but concentrations were low there. If this site is eliminated the average $c_{\mathrm{v}}$ for 2019 and 2020 become significant at the $p_{1}=0.022$. It hints that emissions may show less variation under lockdown, perhaps because larger more constant sources, (power stations) dominate over fluctuating sources, such as small factories or traffic in the absence of congestion etc. An analysis of the posts to Weibo under lockdown reveal that of almost 30000 posts, only 13 mentioned the air pollution (three mention the situation beyond China). Some posts showed an awareness of the NASA satellite observations that $\mathrm{NO}_{2}$ had decreased during lockdown. One post said that "Blue sky and white clouds? The lockdown had been enforced for more than one month, but I still cannot see any blue. so serious is pollution for my city... " and another post: "Well, Wuhan is to be relieved of the lockdown policy tomorrow, but I still can feel the air pollution." This hints at a familiar concern over the temporary nature of these improvements (Brimblecombe and Zong, 2019). After the lockdown period only 9 of some 8000 posts, mentioned air pollution, showing interest in improved air quality world-wide. One post said: "When people stayed at home avoiding COVID-19, air quality in New
Delhi improved, reflecting that air pollution is associated with production. While the air pollution in Wuhan did not vanish during lockdown, so ...it is not just related to industry." Even though official reports said air pollution declined significantly, Wuhan commentators felt it was still there.

Changes in measured $\mathrm{PM}_{2.5}$ are not so apparent from Figs. 6(c) and 6(d), and those for $\mathrm{O}_{3}$ (Figs. 6(e) and 6(f)) not visually impressive. The concentrations of $\mathrm{NO}_{2}, \mathrm{PM}_{2.5}$ and $\mathrm{O}_{3}$ averaged from the urban and suburban sites in Beijing across similar periods are shown in Figs. 6(g)-6(1). Once again, the changes between the years are hardly striking. Reductions in road use in Beijing were substantial. Beijing Municipal Bureau Statistics showed that road movement of people dropping from 52 million in February 2019 to only 8.2 million in 2020 and rose from 10.3 in 2019 to 7.3 million tons in 2020 (http://tjj.beijing.gov.cn/). Nevertheless, large such reductions in traffic flow were likely more apparent in urbanised areas.

Average pollutant concentrations over the lockdown period 23/January-8/April/2020 are compared with 2019 (with one less day duration because 2020 was a leap year) for Wuhan and Beijing in Table 3. The table was assembled from daily averages, calculated from at least 20 hourly measurements at individual sites. Welch's $t$-test (i.e., unequal variances) was used to determine the significance of the difference between the years. The average $\mathrm{NO}_{2}$ concentrations are overall much lower for 2020 (black) and we additionally note that differences in $\mathrm{NO}_{2}$ between the two years were significant $\left(p_{1}<.0001\right)$ across all the nine individual sites (note: individual site data is not displayed in the table). Similarly, the $\mathbf{P M}_{2.5}$ concentrations show a striking difference between the two years with the $t$-test indicating $p_{1}<.0001$. The $\mathrm{PM}_{10}$ data is incomplete, but the raw data hints at decreases. However, we should be cautious in ascribing these differences to the lockdown as it might simply be that weather favoured more dispersion in 2020. Nevertheless, de-weathered data ( Vu et al., 2019; Cole et al., 2020), suggest there were subtle though real changes as a result of lockdown. There is a possibility 

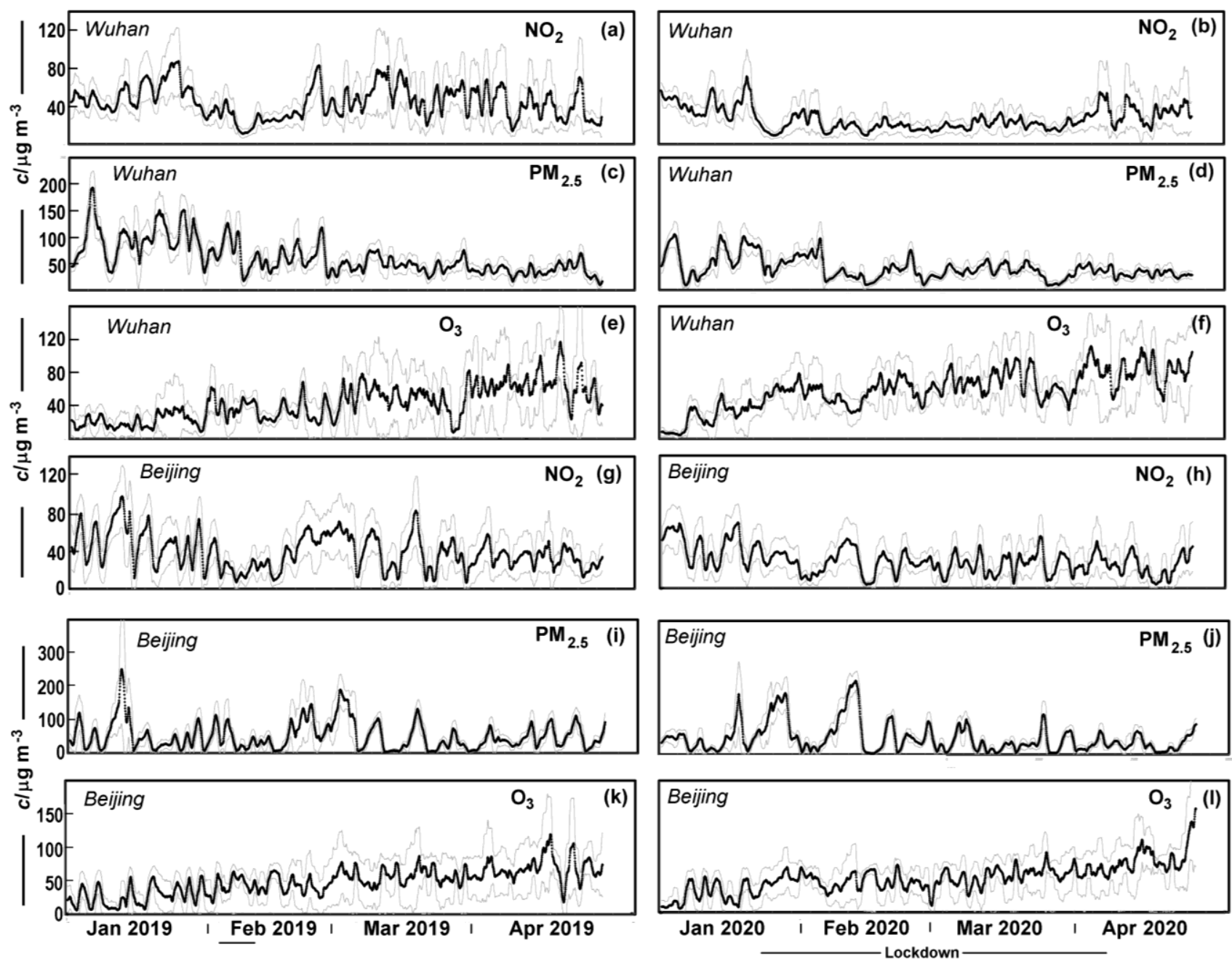

Fig. 6. Running means (25 point i.e., 24 hours, to be representative of daily values) of hourly pollutant concentrations: January to April over all sites in Wuhan and urban and suburban sites in Beijing. The grey lines define the upper and lower bounds of the standard deviation. (a) $\mathrm{NO}_{2}$ in Wuhan 2019, (b) $\mathrm{NO}_{2}$ in Wuhan 2020, (c) $\mathrm{PM}_{2.5}$ in Wuhan 2019, (d) $\mathrm{PM}_{2.5} \mathrm{n}$ Wuhan 2020, (e) $\mathrm{O}_{3}$ in Wuhan 2019, (f) $\mathrm{O}_{3}$ in Wuhan 2020, (g) $\mathrm{NO}_{2}$ in Beijing 2019, (h) $\mathrm{NO}_{2}$ in Beijing 2020, (i) $\mathrm{PM}_{2.5}$ in Beijing 2019, (j) $\mathrm{PM}_{2.5}$ in Beijing 2020, (k) $\mathrm{O}_{3}$ in Beijing 2019 and (l) $\mathrm{O}_{3}$ in Beijing 2020. Note: Chinese New Year of 2019 and the Wuhan lockdown of 2020 are marked as bars below the $x$-axis.

of increased secondary aerosol formation at night under lockdown (Huang et al., 2020) and after sunrise secondary aerosol production has been observed after firework displays (Retama et al., 2019). There also look to be significant decreases in CO (although these were not apparent across all the individual sites) and $\mathrm{SO}_{2}$. We noticed that the rural site near Chenhu Wetland shows higher concentrations in 2020 for both $\mathrm{CO}$ and $\mathrm{SO}_{2}$, although these are not really significant. Ozone as a secondary pollutant, that is often titrated out by NO in urban areas, might well show higher concentrations under lockdown when emissions are lower. This proves to be the case, with average $\mathrm{O}_{3}$ concentrations higher at all sites in $2020\left(p_{1}<.0001\right)$, with the exception of the wetland site $\left(p_{1}=0.03\right)$. Here there is little change in $\mathrm{O}_{3}$, as at this rural site, $\mathrm{NO}_{\mathrm{x}}$ is likely to be low every year.

The picture is less clear for Beijing (Table 3), but the decreases in $\mathrm{NO}_{2}$ and $\mathrm{SO}_{2}$ are significant with a slight increase in $\mathrm{O}_{3}$ of modest significance. The decrease in average $\mathrm{NO}_{2}$ concentrations was more apparent at urban sites (within the $5^{\text {th }}$ Ring Road); understandable as these were more likely to show an effect from COVID-19 restrictions. The average $\mathrm{PM}_{2.5}$ concentrations at the urban sites and suburban sites (beyond the $5^{\text {th }}$ Ring Road) are not especially distinctive; indeed at many sites the concentrations are slightly higher under the restrictions, although the individual differences were significant at two of the 23 sites $\left(p_{1} \sim 0.05\right.$ confidence level as from Welch's t-Test comparing average daily values between the two years). The concentrations of $\mathrm{CO}$ show some sites higher and some to be lower during the restrictions, but none with significant differences $\left(p_{1}>.1\right)$. Ozone concentrations appear higher at all but one of the urban site during the COVID-19 restrictions, although this was only significant $\left(p_{1}<.1\right)$ at only six of these sites.

In general, concentrations for primary pollutants tended to be higher in 2019, although the long secular decrease in emissions (and meteorological differences) might account 
Table 3. Average pollutant concentrations $(c)$ and standard deviations $(\sigma)$ for 2019 and 2020 over the lockdown period extracted from daily average values across the cities. The $p$ value refers to the significance of the difference using Welch's $t$-test. Note: - = record incomplete. $\mu \mathrm{g} \mathrm{m}^{-3}$, except $\mathrm{CO}$ as $\mathrm{mg} \mathrm{m}^{-3}$, Beijing is taken from the 23 urban and suburban sites.

\begin{tabular}{|c|c|c|c|c|c|}
\hline \multirow{2}{*}{ Pollutant } & \multicolumn{2}{|c|}{2019} & \multicolumn{2}{|c|}{2020} & $t$-test \\
\hline & $c$ & $\sigma$ & $c$ & $\sigma$ & $p$ \\
\hline \multicolumn{6}{|l|}{ Wuhan } \\
\hline $\mathrm{NO}_{2}$ & 45.2 & 17.8 & 21.2 & 6.8 & $<.0001$ \\
\hline $\mathrm{PM}_{2.5}$ & 58.5 & 26.5 & 38.0 & 16.8 & $<.0001$ \\
\hline $\mathrm{PM}_{10}$ & 66.4 & 33.8 & 46.2 & 19.7 & $<.0002$ \\
\hline $\mathrm{CO}$ & 1.01 & 0.25 & 0.89 & 0.19 & $<.0005$ \\
\hline $\mathrm{SO}_{2}$ & 8.8 & 3.0 & 7.9 & 2.5 & $<0.03$ \\
\hline $\mathrm{O}_{3}$ & 42.1 & 16.9 & 62.6 & 15.3 & $<.0001$ \\
\hline \multicolumn{6}{|l|}{ Beijing } \\
\hline $\mathrm{NO}_{2}$ & 37.2 & 17.6 & 26.3 & 11.7 & $<.001$ \\
\hline $\mathrm{PM}_{2.5}$ & 50.0 & 40.2 & 53.8 & 50.0 & 0.30 \\
\hline $\mathrm{PM}_{10}$ & 80.8 & 51.6 & - & - & \\
\hline $\mathrm{CO}$ & 0.71 & 0.34 & 0.74 & 0.51 & 0.32 \\
\hline $\mathrm{SO}_{2}$ & 5.8 & 2.8 & 4.2 & 2.4 & $<.001$ \\
\hline $\mathrm{O}_{3}$ & 50.0 & 14.5 & 54.2 & 12.9 & 0.03 \\
\hline
\end{tabular}

for some of this. However, as previously noted the wellrecognised change in $\mathrm{NO}_{2}$ is clear, while the change in particulate concentrations is less significant. The changes in surface $\mathrm{O}_{3}$ are probably regionally variant with an increase in concentrations found across China, especially in Northern regions (Huang et al., 2020; Shi and Brasseur, 2020), along with striking increases in Beijing and Wuhan, but only modest changes in Shanghai and Guangzhou (Zhao et al., 2020).

Weekly cycles can reveal the variations in social behaviour and are a good indicator of human effects on air pollutants. These are likely to be less sensitive to changes in climate between years. Diurnal cycles in Wuhan for 2019 and 2020 over the days of lockdown are seen in Fig. 7, which shows hourly averages (across all sites) separating weekdays and weekends (i.e., non-work days which include Saturdays, Sundays and public holidays). The $\mathrm{NO}_{2}$ concentrations are obviously much lower in 2020 (Fig. 7(b)), and although the diurnal pattern is similar for each year, i.e., minimum in the early afternoon and maximum in the early evening, there are subtle differences. Weekday/weekends cycles are similar for 2019 with weekday and weekend means of 45.4 and 44.5 $\mu \mathrm{g} \mathrm{m}^{-3}$, a difference that is barely significant from a $t$-test $\left(p_{1}\right.$ $=0.04)$ paired across sites. Under lockdown these are 21.2 and $19.2 \mu \mathrm{g} \mathrm{m}^{-3}$, a significant difference $\left(p_{1}<.0001\right)$ that arises from higher values at night over the weekends. In 2019, weekends revealed slightly higher concentrations of $\mathrm{PM}_{2.5}$ throughout the day (56 and $64 \mu \mathrm{g} \mathrm{m}^{-3} ; p_{1}<.0001$ ); perhaps people enjoying an evening out, while under lockdown these concentrations were typically lower during the weekends (39.0 and $34.5 \mu \mathrm{g} \mathrm{m}^{-3} ; p_{1}<.0001$ ). The changes likely arose from the restriction of outdoor weekend activities likely to generate $\mathrm{PM}_{2.5}$. Weekends under lockdown shows $\mathrm{PM}_{2.5}$ concentrations that are almost invariant through the day. The $t$-test, paired across sites, showed that the weekday and weekend concentrations of CO in 2019 were almost identical, with no significant differences in concentrations (1.011 and $1.014 \mathrm{mg} \mathrm{m}^{-3} ; p_{1}=0.27$ ). Under lockdown in 2020 , as with particles there is a slight, though significant decrease in the concentrations during weekends $\left(0.899\right.$ and $0.857 \mathrm{mg} \mathrm{m}^{-3}$; $\left.p_{1}<.0001\right)$, which show less of a daily cycle.

\section{Discussion}

The effect of celebratory fireworks, the Chinese New Year holiday and the lockdown restrictions, as a response to the COVID-19 pandemic, all left signatures on the atmospheric environment. The effect of fireworks is evident in elevated particulate concentrations during brief periods of celebration, though increasing regulation has come to limit the effect and seems to have gradually pushed any peaks to the outer margins of Chinese cities (Lai and Brimblecombe, 2017, 2020). The holiday effect, while much discussed in the past, seems limited to the nitrogen oxides, and difficult to detect in Wuhan and Beijing. Contemporary social behaviour may allow emissions to remain relatively high even during the holidays and result in a decline in the magnitude of the holiday effect, which aligns with trends in the holiday effect observed elsewhere in the region (Kim et al., 2020).

Bao and Zhang (2020) show broad improvements in $\mathrm{SO}_{2}$, $\mathrm{PM}_{2.5}, \mathrm{PM}_{10}, \mathrm{NO}_{2}$, and $\mathrm{CO}$ across 44 Chinese cities of the Jingjinji megalopolis, 1/January-21/March/2020. Although lockdown had an impact on air quality, it is necessary to recognise the subtlety of the changes. It has been popular in publications to assert a reduction of air pollutants in lockdown by comparing the period immediately before and after or alternatively comparing 2020 with 2019; indeed this paper adopts such methods, but the changing seasons and weather can make comparisons difficult. As Cole et al., (2020) rightly argue, even after de-weathering the data: "Our results indicate that the impact of the lockdown varied by pollutant, a nuance that newspaper reports of cleaner postlockdown air have generally failed to acknowledge." They note that while $\mathrm{PM}_{10}$ concentrations declined, this was for a shorter period. Our work agrees with this and suggests the case for improved $\mathrm{CO}$ and $\mathrm{SO}_{2}$ is even less convincing. The effects in Beijing are necessarily subtle given the restrained response to COVID-19 in the capital, though these are 


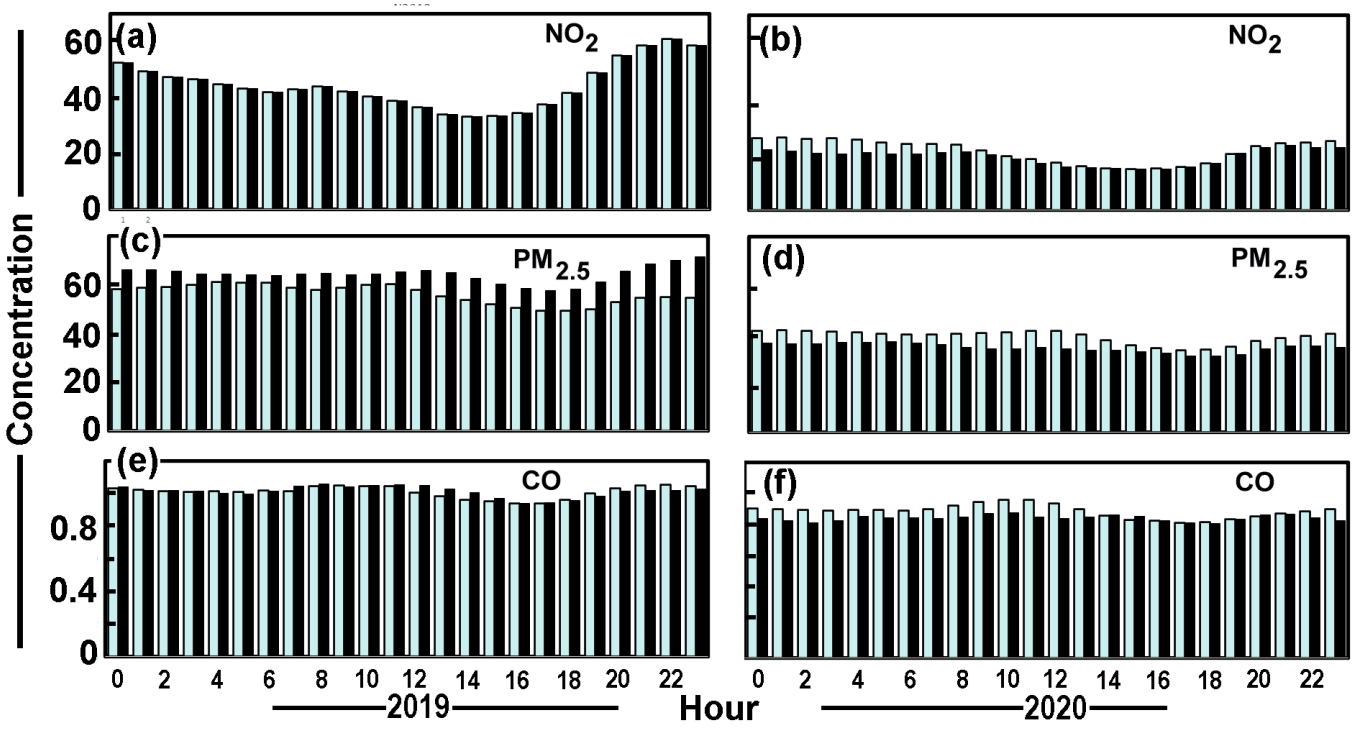

Fig. 7. Diurnal plot as hourly average concentrations from all sites in Wuhan for weekdays (light bars) and weekends (dark bars) across the period 23/Jan to 7/April for 2019 and 2020 (representing lockdown for the latter year) for (a) $\mathrm{NO}_{2}$ in 2019 , (b) $\mathrm{NO}_{2}$ in 2020, (c) $\mathrm{PM}_{2.5}$ in 2019, (d) $\mathrm{PM}_{2.5}$ in 2020, (e) CO in 2019 and (f) $\mathrm{CO}$ in 2020. Note: concentrations as $\mu \mathrm{g} \mathrm{m}^{-3}$, for $\mathrm{NO}_{2}$ in 2020 and $\mathrm{PM}_{2.5}$ while $\mathrm{CO}$ is as $\mathrm{mg} \mathrm{m}^{-3}$.

clearest for urban $\mathrm{NO}_{2}$. Increases in ozone through a lack of titration by NO are apparent, but are clearer in urban Wuhan, while less significant in the surrounding countryside, where $\mathrm{NO}_{\mathrm{x}}$ is inevitably lower. Such issues may well limit the spread of ozone increases more regionally (Xu et al., 2020).

\section{CONCLUSIONS}

While peaks in $\mathrm{PM}_{2.5}$ in the early morning of New Year were once characteristic of Chinese cities, regulations have reduced their occurrence such that they only persist in less populated areas. The holiday effect is now rather indistinct, given the variation of activities even during holidays under COVID-19 period, while the fireworks effects in some places (i.e., rural areas) still can be observed although the firework peak at midnight on the eve Chinese New Year is smaller than in the past because of increasing regulatory restriction. During lockdown, Weibo users showed a concern that the air pollution, perhaps "temporarily lost, would be found again once it ended", with social media thus revealing citizen concern about long term improvement to air quality. Views, expressed across much of the world, suggest we should use the pandemic as a catalyst for broad environmental improvement, much as John Evelyn saw London's Great Fire of 1666 as a chance to replan the city (http://digitalarchive.mc master.ca/islandora/object/macrepo\%3A31438), remove pollutant sources within London, and place them downwind of the metropolis. Arguments that pollution exposure has been reduced by COVID-19 lockdown and actually saved lives may be more difficult to establish, because the improvements in air quality can be subtle, spatially limited and not always long-lived. As most people are indoors during the lockdown it is also necessary to consider indoor exposure in estimating health outcomes. This means that although ozone concentrations were enhanced in urban agglomerations under lockdown (less apparent in the countryside), it is possible that ozone will not be strongly transferred indoors. Research has considered the primary rather than secondary aerosol, so this may represent a further area for study. While the first wave of the COVID-19 pandemic may have been short, it has given us much to think about the relation between human activity and our environment.

\section{ACKNOWLEDGMENTS}

The authors wish to thank Eliani EZANI for her insistence on the importance of different indoor activities under lockdown.

\section{REFERENCES}

Abdullah, S., Mansor, A.A., Napi, N.N.L.M., Mansor, W.N.W., Ahmed, A.N., Ismail, M. and Ramly, Z.T.A. (2020). Air quality status during 2020 Malaysia Movement Control Order (MCO) due to 2019 novel coronavirus (2019-nCoV) pandemic. Sci. Total Environ. 729: 139022. https://doi.org/10.1016/j.scitotenv.2020.139022

Bao, R. and Zhang, A. (2020). Does lockdown reduce air pollution? Evidence from 44 cities in northern China. Sci. Total Environ. 139052. https://doi.org/10.1016/j.scitotenv. 2020.139052

Bauwens, M., Compernolle, S., Stavrakou, T., Müller, J.F., van Gent, J., Eskes, H., Levelt, P.F., van der A.R., Veefkind, J.P., Vlietinck, J. and Yu, H., (2020). Impact of coronavirus outbreak on $\mathrm{NO}_{2}$ pollution assessed using TROPOMI and OMI observations. Geophys. Res. Lett. 7: e2020GL087978. https://doi.org/10.1029/2020GL087978

Brimblecombe, P. and Ning, Z. (2015). Effect of road blockages on local air pollution during the Hong Kong protests and its implications for air quality management. 
Sci. Total Environ. 536: 443-448. https://doi.org/10.1016/ j.scitotenv.2015.07.104

Brimblecombe, P. and Zong, H. (2019). Citizen perception of APEC blue and air pollution management. Atmos. Environ. 214: 116853. https://doi.org/10.1016/j.atmosenv. 2019.116853

Brimblecombe, P. (2020a). Street protests and air pollution in Hong Kong. Environ. Monit. Assess. 192: 259. https://doi.org/10.1007/s10661-020-8243-0

Brimblecombe, P. (2020b). A journal in a plague year. City Environ. Interact. 4: 100028. https://doi.org/10.1016/j.ca cint.2020.100028

Brosseau, L.M., Evans, J.L., Ellenbecker, M.J. and Feldstein, M.L. (1989). Collection efficiency of respirator filters challenged with monodisperse latex aerosols. Am. Ind. Hyg. Assoc. J. 50: 544-549. https://doi.org/10.1080/ 15298668991375137

Cerro, J.C., Cerda, V. and Pey, J. (2014). Trends of air pollution in the Western Mediterranean Basin from a 13year database: A research considering regional, suburban and urban environments in Mallorca (Balearic Islands). Atmos. Environ. 103: 138-146. https://doi.org/10.1016/j. atmosenv.2014.12.014

Charell, P.R. and Hawley, R.E. (1981). Characteristics of water adsorption on air sampling filters. Am. Ind. Hyg. Assoc. J. 42: 353-360. https://doi.org/10.1080/15298668 191419875

Chen, X., Liu, Z. and Wu, P.L. (2014). Analysis on Chinese urban air quality "Spring Festival Effect": Evidence from 31 key cities in China. Stat. Inf. Forum 29: 57-62. (Chinese)

Cheng, H., Zhang, W., Wang, Q., Wan, W. and Du, X. (2018). Breakthroughs, China's Path to Clean Air 20132017. Clean Air Asia, China Office Beijing.

Cole, M., Elliott, R. and Liu, B. (2020). The impact of the Wuhan Covid-19 lockdown on air pollution and health: A machine learning and augmented synthetic control approach. Department of Economics, University of Birmingham.

Crittenden, B.D. and Long, R. (1976). In Carcinogenesis--A comprehensive survey, Vol. 1, Freudenthal, R.I. and Jones, P.W. (Eds.), Raven Press, New York, 209.

Cui, Y., Ji, D., Maenhaut W., Gao, W., Zhang, R., and Wang, Y. (2020). Levels and sources of hourly $\mathrm{PM}_{2.5}$ related elements during the control period of the COVID19 pandemic at a rural site between Beijing and Tianjin. Sci. Total Environ. 744: 140840. https://doi.org/10.1016/ j.scitotenv.2020.140840

Dantas, G., Siciliano, B., França, B.B., da Silva, C.M. and Arbilla, G. (2020). The impact of COVID-19 partial lockdown on the air quality of the city of Rio de Janeiro, Brazil. Sci. Total Environ. 729: 139085. https://doi.org/1 0.1016/j.scitotenv.2020.139085

Dutheil, F., Baker, J. S. and Navel, V. (2020). COVID-19 as a factor influencing air pollution? Environ. Pollut. 263: 114466. https://doi.org/10.1016/j.envpol.2020.114466

Feng, J., Yu, H., Su, X., Liu, S., Li, Y., Pan, Y, and Sun, J.H. (2016). Chemical composition and source apportionment of $\mathrm{PM}_{2.5}$ during Chinese Spring Festival at Xinxiang, a heavily polluted city in North China: fireworks and health risks. Atmos. Res. 182: 176-188. https://doi.org/10.1016/j. atmosres.2016.07.028

Gong, D.Y., Wang, W., Qian, Y., Bai, W., Guo, Y. and Mao, R. (2014). Observed holiday aerosol reduction and temperature cooling over East Asia. J. Geophys. Res. 119: 6306-6324. https://doi.org/10.1002/2014jd021464

Han, G., Gong, W., Quan, J.H., Li, J. and Zhang, M. (2014). Spatial and temporal distributions of contaminants emitted because of Chinese New Year's Eve celebrations in Wuhan. Environ. Sci. Process Impacts 16: 916-923. https://doi.org/10.1039/c3em00588g

Henschel, S., Tertre, A.L., Atkinson, R.W., Querol, X., Pandolfi, M., Zeka, A., Haluza, D., Analitis, A., Katsouyanni, K., Bouland, C., Pascal, M., Medina, S. and Goodman, P.G. (2015). Trends of nitrogen oxides in ambient air in nine European cities between 1999 and 2010. Atmos. Environ. 117: 234-241. https://doi.org/10.1 016/j.atmosenv.2015.07.013

Hinds, W.C. and Bellin, P. (1988). Effect of facial-seal leaks on protection provided by half-mask respirator. Appl. Ind. Hyg. 3: 158-164. https://doi.org/10.1080/08828032.1988. 10388550

Hu, B., Duan, J., Liu, S., Hu, J., Zhang, M., Kang, P. and Wang, C. (2019). Evaluation of the effect of fireworks prohibition in the Beijing-Tianjin-Hebei and surrounding areas during the Spring Festival of 2018. Res. Environ. Sci. 32: 203-211. (Chinese)

Huang, K., Zhuang, G., Lin, Y., Wang, Q., Fu, J.S., Zhang, R., Li, J. and Deng, F.Q. (2012). Impact of anthropogenic emission on air quality over a megacity -revealed from an intensive atmospheric campaign during the Chinese Spring Festival. Atmos. Chem. Phys. 12: 11631-11645. https://doi.org/10.5194/acp-12-11631-2012

Huang, X., Ding, A., Gao, J., Zheng, B., Zhou, D., Qi, X., Tang, R., Wang, J., Ren, C., Nie, W. and Chi, X. (2020). Enhanced secondary pollution offset reduction of primary emissions during COVID-19 lockdown in China. Natl. Sci. Rev. nwaa137. https://doi.org/10.1093/nsr/nwaa137

Huryn, S.M. and Gough, W.A. (2014). Impact of urbanization on the ozone weekday/weekend effect in Southern Ontario, Canada. Urban Clim. 8: 11-20. https://doi.org/10. 1016/j.uclim.2014.03.005

Ji, D., Cui, Y., Li, L., He, J., Wang, L., Zhang, H., Wang, W., Zhou, L., Maenhaut, W., Wen, T. and Wang, Y. (2018). Characterization and source identification of fine particulate matter in urban Beijing during the 2015 Spring Festival. Sci. Total Environ. 628-629: 430-440. https://doi.org/10.1016/j.scitotenv.2018.01.304

Kerker, M. (1969). The scattering of light. Academic Press, New York.

Kim, J.W., Han, B.S. and Baik, J.J. (2020). Temporal and spatial variations of workday-holiday particulate matter concentration differences in Seoul. J. Korean Soc. Atmos. Environ. 36: 25-30. https://doi.org/10.5572/KOSAE.202 0.36.1.025

Kinniburgh, C. (2019). Climate politics after the yellow vests. Dissent 66: 115-125. https://doi.org/10.1353/dss.2 019.0037 
Kong, S., Li, X., Li, L., Yin, Y., Chen, K., Yuan, L, Zhang, Y., Shan, Y. and Ji, Y. (2015). Variation of polycyclic aromatic hydrocarbons in atmospheric $\mathrm{PM}_{2.5}$ during winter haze period around 2014 Chinese Spring Festival at Nanjing: Insights of source changes, air mass direction and fireworks particle injection. Sci. Total Environ. 520: 59-72. https://doi.org/10.1016/j.scitotenv.2015.03.001

Lai, I.C. and Brimblecombe, P. (2020). Long range transport of air pollutants to Taiwan during the COVID-19 lockdown in Hubei province. Aerosol Air Qual. Res., in review.

Lai, Y. and Brimblecombe, P. (2017). Regulatory effects on particulate pollution in the early hours of Chinese New Year, 2015. Environ. Monit. Assess. 189: 467. https://doi.org/10.1007/s10661-017-6167-0

Lai, Y. and Brimblecombe, P. (2020). Changes in air pollution and attitude to fireworks in Beijing. Atmos. Environ. 231: 117549. https://doi.org/10.1016/j.atmosenv. 2020.117549

Levy, I. (2013). A national day with near zero emissions and its effect on primary and secondary pollutants. Atmos. Environ. 77: 202-212. https://doi.org/10.1016/j.atmosenv. 2013.05.005

Lewis, A. (2020) Air pollution falling across UK cities, latest data shows. National Centre for Atmospheric Science. https://www.ncas.ac.uk/en/18-news/3057-airpollution-falling-across-uk-cities-latest-data-shows

Li, L., Li, J., Xin, L., Li, H. and Wei, Q. (2006). Analysis of atmospheric air pollution of Beijing City in Spring Festival period. China Environ. Sci. 26: 537-541. (in Chinese)

Lian, X., Huang, J., Huang, R., Liu, C., Wang, L. and Zhang, T. (2020). Impact of city lockdown on the air quality of COVID-19-hit of Wuhan city. Sci. Total Environ. 742: 140556. https://doi.org/10.1016/j.scitotenv.2020.140556

Liu, F., Page, A., Strode, S.A., Yoshida, Y., Choi, S., Zheng, B., Lamsal, L.N., Li, C., Krotkov, N.A., Eskes, H. and Veefkind, P. (2020). Abrupt decline in tropospheric nitrogen dioxide over China after the outbreak of COVID19. Sci. Adv. 6: eabc2992. https://doi.org/10.1126/sciadv. abc2992

Liu, H., Kobernus, M. and Liu, H. (2017). Public perception survey study on air quality issues in Wuhan, China. $J$. Environ. Prot. 8: 1194-1218. https://doi.org/10.4236/jep. 2017.810075

Malik, A. and Tauler, R. (2015). Exploring the interaction between $\mathrm{O}_{3}$ and $\mathrm{NO}_{x}$ pollution patterns in the atmosphere of Barcelona, Spain using the MCR-ALS method. Sci. Total. Environ. 517: 151-161. https://doi.org/10.1016/j.s citotenv.2015.01.105

Martins, E.M., Nunes, A.C.L. and Correa, S.M. (2015). Understanding ozone concentrations during weekdays and weekends in the urban area of the city of Rio de Janeiro. J. Braz. Chem. Soc. 26: 1967-1975. https://doi.org/10.5935/0103-5053.20150175

Mohd Nadzir, M.S., Chel Gee Ooi, M., Alhasa, K.M., Bakar, M.A.A., Mohtar, A.A.A., Mohd Nor, M.F.F., Latif, M.T., Abd Hamid, H.H., Md Ali, S.H., Ariff, N.M., Anuar, J., Ahamad, F., Azhari, A., Hanif, N.M., Subhi, M.A.,
Othman, M. and Mohd Nor, M.Z. (2020). The impact of movement control order (MCO) during pandemic COVID-19 on local air quality in an urban area of Klang Valley, Malaysia. Aerosol Air Qual. Res. 20: 1237-1248. https://doi.org/10.4209/aaqr.2020.04.0163

Muhammad, S., Long, X. and Salman, M. (2020). COVID19 pandemic and environmental pollution: A blessing in disguise? Sci. Total Environ. 728: 138820. https://doi.org/10.1016/j.scitotenv.2020.138820

Nakada, L.Y.K. and Urban, R.C. (2020). COVID-19 pandemic: Impacts on the air quality during the partial lockdown in São Paulo state, Brazil. Sci. Total Environ. 730: 139087. https://doi.org/10.1016/j.scitotenv.2020.13 9087

Narajewski, M. and Ziel, F. (2020). Changes in electricity demand pattern in Europe due to COVID-19 shutdowns. arXiv:2004.14864.

Porter, W.C., Khalil, M.A.K., Butenhoff, C.L., Almazroui, M., Al-Khalaf, A.K. and Al-Sahafi, M.S. (2014). Annual and weekly patterns of ozone and particulate matter in Jeddah, Saudi Arabia. J. Air Waste Manage. Assoc. 64: 817-826. https://doi.org/10.1080/10962247.2014.893931

Preuss, H. (2013). The contribution of the FIFA World Cup and the Olympic Games to green economy. Sustainability 5: 3581-3600. https://doi.org/10.3390/su5083581

Pudasainee, D., Sapkota, B., Bhatnagar, A., Kim, S.H. and Seo, Y.C. (2010). Influence of weekdays, weekends, and bandhas on surface ozone in Kathmandu valley. Atmos. Res. 95: 150-156. https://doi.org/10.1016/j.atmosres.200 9.09.007

Qin, Y., Tonnesen, G.S. and Wang, Z. (2004). Weekend/weekday differences of ozone, $\mathrm{NO}_{\mathrm{x}}, \mathrm{CO}$, VOCs, $\mathrm{PM}_{10}$ and the light scatter during ozone season in southern California. Atmos. Environ. 38: 3069-3087. https://doi.org/10.1016/j.atmosenv.2004.01.035

Retama, A., Neria-Hernández, A., Jaimes-Palomera, M., Rivera-Hernández, O., Sánchez-Rodríguez, M., LópezMedina, A. and Velasco, E. (2019). Fireworks: A major source of inorganic and organic aerosols during Christmas and New Year in Mexico city. Atmos. Environ. 2: 100013. https://doi.org/10.1016/j.aeaoa.2019.100013

Riga-Karandinos, A.N. and Saitanis, C. (2005). Comparative assessment of ambient air quality in two typical Mediterranean coastal cities in Greece. Chemosphere 59: 1125-1136. https://doi.org/10.1016/j.chemosphere.2004. 11.059

Sadanaga, Y., Sengen, M., Takenaka, N. and Bandow, H. (2012). Analyses of the ozone weekend effect in Tokyo, Japan: Regime of oxidant $\left(\mathrm{O}_{3}+\mathrm{NO}_{2}\right)$ production. Aerosol Air Qual. Res. 12: 161-168. https://doi.org/10.4209/aaqr. 2011.07.0102

Safarian, S., Unnthorsson, R. and Richter, C. (2020). Effect of coronavirus disease 2019 on $\mathrm{CO}_{2}$ emission in the world. Aerosol Air Qual. Res. 20: 1197-1203. https://doi.org/10.4209/aaqr.2020.04.0151

Servick, K. and Enserink M. (2020). A mysterious company's coronavirus papers in top medical journals may be unraveling. Science. https://doi.org/10.1126/science.abd1 337 
Sharma, S., Zhang, M., Gao, J., Zhang, H. and Kota, S. H. (2020). Effect of restricted emissions during COVID-19 on air quality in India. Sci. Total Environ. 728: 138878. https://doi.org/10.1016/j.scitotenv.2020.138878

Shi, X. and Brasseur, G.P. (2020). Response in air quality to the reduction of Chinese economic activities during the COVID-19 outbreak. Geophys. Res. Lett. 47: e2020GL088070. https://doi.org/10.1029/2020GL088070

Sun, S. (2017). An analysis of the influence of a fireworks display process on the air quality of Beijing. Sci. Tech. Inf. Gansu 46: 27-30. (in Chinese)

Tan, P.H., Chou, C., Liang, J.Y., Chou, C.C.K. and Shiu, C.J. (2009). Air pollution "holiday effect" resulting from the Chinese New Year. Atmos. Environ. 43: 2114-2124. https://doi.org/10.1016/j.atmosenv.2009.01.037

Tang, W.Y., Zhao, C.S., Geng, F.H., Peng, L., Zhou, G.Q., Gao, W., Xu, J.M. and Tie, X.X. (2008). Study of ozone "weekend effect" in Shanghai. Sci. China Ser. D Earth Sci. 51: 1354-1360. https://doi.org/10.1007/s11430-0080088-2

Tobías, A., Carnerero, C., Reche, C., Massagué, J., Via, M., Minguillón, M.C., Alastuey, A. and Querol, X. (2020). Changes in air quality during the lockdown in Barcelona (Spain) one month into the SARS-CoV-2 epidemic. Sci. Total Environ. 726: 138540. https://doi.org/10.1016/j.sci totenv.2020.138540

Tsai, Y.I., Sopajaree, K., Kuo, S.C. and Yu, S.P. (2015). Potential $\mathrm{PM}_{2.5}$ impacts of festival-related burning and other inputs on air quality in an urban area of southern Taiwan. Sci. Total Environ. 527-528: 65-79. https://doi.org/10.1016/j.scitotenv.2015.04.021

Vannest, K.J., Parker, R.I., Gonen, O. and Adiguzel, T. (2016). Single Case Research: Web based calculators for SCR analysis. (Version 2.0) [Web-based application]. College Station, TX: Texas A\&M University. http://www.singlecaseresearch.org/

Vu, T.V., Shi, Z., Cheng, J., Zhang, Q., He, K., Wang, S. and Harrison, R.M. (2019). Assessing the impact of clean air action on air quality trends in Beijing using a machine learning technique. Atmos. Chem. Phys. 19: 1130311314. https://doi.org/10.5194/acp-19-11303-2019

Wang, B. (2015). Study of the Calculation Method of the Influence of Fireworks Setting off on Atmospheric $\mathrm{PM}_{2.5}$. Value Eng. 34: 59-61. (in Chinese)

Wang, P., Chen, K., Zhu, S., Wang, P. and Zhang, H. (2020). Severe air pollution events not avoided by reduced anthropogenic activities during COVID-19 outbreak. Resour. Conserv. Recycl. 158: 104814. https://doi.org/10. 1016/j.resconrec.2020.104814

Wang, Q. and Su, M. (2020). A preliminary assessment of the impact of COVID-19 on environment-A case study of China. Sci. Total Environ. 728: 138915. https://doi.org/10. 1016/j.scitotenv.2020.138915

Wang, T., Wang, P., Hendrick, F. and Van Roozendael, M. (2018). Re-examine the APEC blue in Beijing 2014. $J$. Atmos. Chem. 75: 235-246. https://doi.org/10.1007/s10874018-9374-3

Wang, Y., Xue, Y., Tian, H., Gao, J., Chen, Y., Zhu, C., Liu, H., Wang, K., Hua, S., Liu, S. and Shao, P. (2017).
Effectiveness of temporary control measures for lowering $\mathrm{PM}_{2.5}$ pollution in Beijing and the implications. Atmos. Environ. 157: 75-83. https://doi.org/10.1016/j.atmosenv. 2017.03.017

Wang, Z., Li, Y., Sun, F., Zhang, D., Qiu, Q., Sun, N. and Pan, L. (2016). Study on the effect of burning of fireworks on air quality in Beijing. Environ. Monit. China 32: 1521. (in Chinese)

Wilson, A. (2013). Embracing Bayes factors for key item analysis in corpus linguistics. In New approaches to the study of linguistic variability. Language Competence and Language Awareness in Europe. Peter Lang, Frankfurt, pp. 3-11.

Wolff, G.T., Kahlbaum, D.F. and Heuss, J.M. (2013). The vanishing ozone weekday/weekend effect. J. Air Waste Manage. Assoc. 63: 292-299. https://doi.org/10.1080/109 62247.2012 .749312

Wu, X., Nethery, R.C., Sabath, B.M., Braun, D. and Dominici, F. (2020). Exposure to air pollution and COVID-19 mortality in the United States. medRxiv 2020.04.05.20054502. https://doi.org/10.1101/2020.04.0 5.20054502

Xie, M., Zhu, K.G., Wang, T.J., Chen, P.L., Han, Y., Li, S., Zhuang, B.L. and Shu, L. (2016). Temporal characterization and regional contribution to $\mathrm{O}_{3}$ and $\mathrm{NO}_{x}$ at an urban and a suburban site in Nanjing, China. Sci. Total. Environ. 551-552: 533-545. https://doi.org/10.1016/j.scitotenv.20 16.02 .047

Xu, K., Cui, K., Young, L.H., Wang, Y.F., Hsieh, Y.K., Wan, S. and Zhang, J. (2020). Air quality index, indicatory air pollutants and impact of COVID-19 event on the air quality near central China. Aerosol Air Qual. Res. 20: 1204-1221. https://doi.org/10.4209/aaqr.2020.04.0139

Yang, M., Fan, H. and Zhao, K. (2020). Fine-grained spatiotemporal analysis of the impact of restricting factories, motor vehicles, and fireworks on air pollution. Int. J. Environ. Res. Public Health 17: 4828. https://doi.org/10.3390/ijerph17134828

Yao, L., Wang, D., Fu, Q., Qiao, L., Wang, H., Li, L., Sun, W., Li, Q., Wang, L., Yang, X., Zhao, Z., Kan, H., Xian, A., Wang, G., Xiao, H. and Chen, J. (2019). The effects of firework regulation on air quality and public health during the Chinese Spring Festival from 2013 to 2017 in a Chinese megacity. Environ. Int. 126: 96-106. https://doi.org/10.1016/j.envint.2019.01.037

Ye, C., Chen, R. and Chen, M. (2016). The impacts of Chinese Nian culture on air pollution. J. Cleaner Prod. 112: 1740-1745. https://doi.org/10.1016/j.jclepro.2015.0 4.113

Yuan, L., Zhang, X., Feng, M., Liu, X., Che, Y., Xu, H., Schaefer, K., Wang, S. and Zhou, Y. (2020). Size-resolved hygroscopic behaviour and mixing state of submicron aerosols in a megacity of the Sichuan Basin during pollution and fireworks episodes. Atmos. Environ. 226: 117393. https://doi.org/10.5194/egusphere-egu2020-2499

Yue, X., Lei, Y., Zhou, H., Liu, Z., Letu, H., Cai, Z., Lin, J., Jiang, Z. and Liao, H. (2020). Changes of anthropogenic carbon emissions and air pollutants during the COVID-19 epidemic in China. Trans. Atmos. Sci. 43: 265-274. (in 
Chinese) https://doi.org/10.13878/j.cnki.dqkxxb.202004 08010

Zhao, S., Yu, Y., Yin, D., Liu, N. and He, J. (2014). Ambient particulate pollution during Chinese Spring Festival in urban Lanzhou, Northwestern China. Atmos. Pollut. Res. 5: 335-343. https://doi.org/10.5094/apr.2014.039

Zhao, Y., Zhang, K., Xu, X. and Shen, H. (2020) Substantial changes in nitrate oxide and ozone after excluding meteorological impacts during the COVID-19 outbreak in mainland China. Environ. Sci. Technol. Lett. 7: 402-408. https://doi.org/10.1021/acs.estlett.0c00304

Received for review, June 16, 2020 Revised, September 23, 2020 Accepted, September 24, 2020 